\title{
Supramolecular FRET photocyclodimerization of anthracenecarboxylate with naphthalene-capped Y-cyclodextrin
}

\author{
Qian Wang ${ }^{1,2}$, Cheng Yang ${ }^{*}$, Gaku Fukuhara ${ }^{1}$, Tadashi Mori ${ }^{1}$, Yu Liu ${ }^{2}$ \\ and Yoshihisa Inoue ${ }^{* 1}$
}

\author{
Full Research Paper \\ Address: \\ 1Department of Applied Chemistry, Osaka University, 2-1 \\ Yamada-oka, Suita 565-0871, Japan and ${ }^{2}$ Department of Chemistry \\ and State Key Laboratory of Elemento-Organic Chemistry, Nankai \\ University Tianjin, 300071 (China) \\ Email: \\ Cheng Yang* - c.yang@chem.eng.osaka-u.ac.jp;

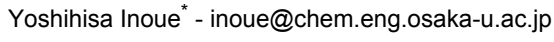 \\ * Corresponding author \\ Keywords: \\ anthracenecarboxylic acid; capped $\mathrm{Y}$-cyclodextrin; FRET sensitization; \\ photochirogenesis; photocyclodimerization
}

Open Access

\author{
Beilstein J. Org. Chem. 2011, 7, 290-297. \\ doi:10.3762/bjoc. 7.38 \\ Received: 06 December 2010 \\ Accepted: 04 February 2011 \\ Published: 07 March 2011 \\ Sakurai and Prof. Tadao Hakushi. \\ Guest Editor: A. G. Griesbeck \\ (C) 2011 Wang et al; licensee Beilstein-Institut. \\ License and terms: see end of document.
}

This article is part of the Thematic Series "Photocycloadditions and photorearrangements" and is dedicated to the memory of Prof. Hiroshi

\begin{abstract}
$\gamma$-Cyclodextrin (CD) derivatives with a naphthalene moiety anchored to one or two of the glucose units of the CD were synthesized in order to investigate the effects of flexible and rigid capping upon complexation, as well as Förster resonance energy transfer (FRET) and photochirogenic behavior of anthracenecarboxylate (AC) moieties. UV-vis, circular dichroism and fluorescence spectral studies revealed that two AC molecules are simultaneously included in the modified $\gamma$-CD cavity to form a right-handed screw and also that the naphthalene cap efficiently transfers the singlet energy to AC included in the CD cavity via the FRET mechanism. Compared to native $\gamma$-CD, the modified $\gamma$-CDs showed much higher first association constants $\left(K_{1}\right)$ but relatively lower second association constants $\left(K_{2}\right)$ for AC, leading to two-fold larger overall affinities $\left(K_{1} K_{2}\right)$. Photocyclodimerization of AC with these modified $\gamma$-CDs produced more head-to-head $(\mathrm{HH})$ dimers in much better enantiomeric excesses (ee) for anti-HH dimer compared to native $\gamma$-CD. Interestingly, FRET excitation further enhanced the chemical and optical yields of anti-HH dimer up to $36 \%$ and $35 \%$ ee, for which the highly efficient FRET sensitization within the CD cavity, minimizing the "contamination" from the achiral "outside" photoreaction, is responsible. FRET sensitization also enabled us to achieve the catalytic photocyclodimerization of AC with a sub-equivalent amount of chiral supramolecular host.
\end{abstract}

\section{Introduction}

Chiral photochemistry, often characterized by low optical yields, remains a great challenge for chemists [1-3]. This situation reflects primarily the difficulty in efficiently transferring

the stereochemical information of the chiral source to the substrate in the electronically excited state. Thus, a supramolecular approach in chiral photochemistry could be a promising strategy 
for critically controlling the stereochemical outcome via intimate, long-lasting contacts with the photosubstrate through noncovalent interactions in the ground state [4-11]. The geometrical and functional complementarity and the subsequent induced fit between chiral host and guest substrate should play a crucial role in determining the stereochemical fate of chiral photoreaction, and therefore the design of chiral host is considered to be one of the most important aspects for manipulating stereoselectivity in supramolecular photochirogenesis.
We have recently focused our attention on enantiodifferentiation in the photocyclodimerization of anthracenecarboxylate (AC) as a representative bimolecular photochirogenic system for the elucidation of the factors and mechanism that control supramolecular photochirogenesis [12-22]. Photocyclodimerization of AC leads to the formation of four stereoisomeric cyclodimers 1-4, of which syn-head-to-tail (HT) 2 and anti-head-to-head (HH) 3 are chiral (Scheme 1). This chiral photoreaction turned out to be an ideal benchmark system for

2<smiles>ClC(Cl)(Cl)c1ccc2cc3ccccc3cc2c1</smiles>

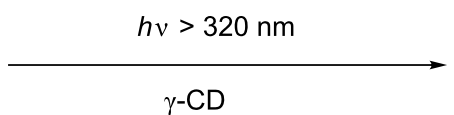<smiles>COC(=O)c1ccc2c(c1)C1c3ccccc3C3c4ccccc4C2(c2ccccc23)C1C(=O)[O-]</smiles>

1

anti-HT

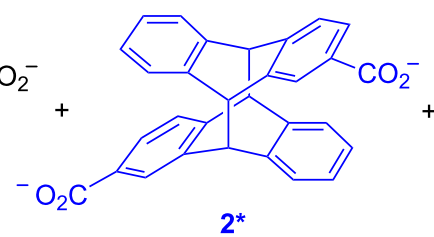

syn-HT

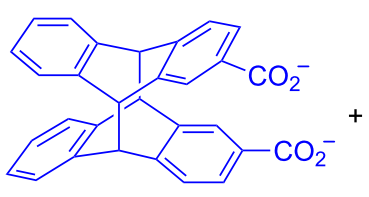

3*

anti-HH

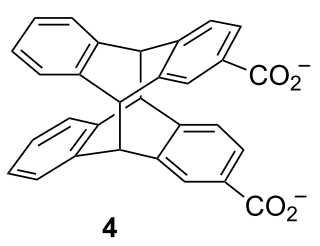

syn-HH

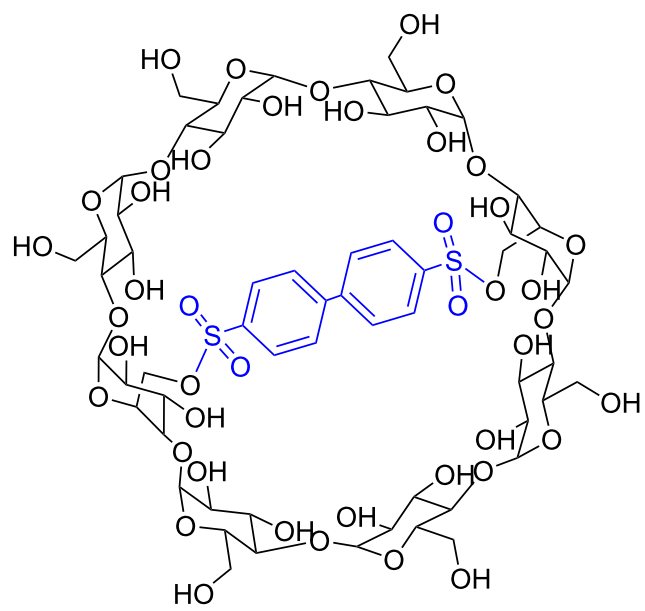

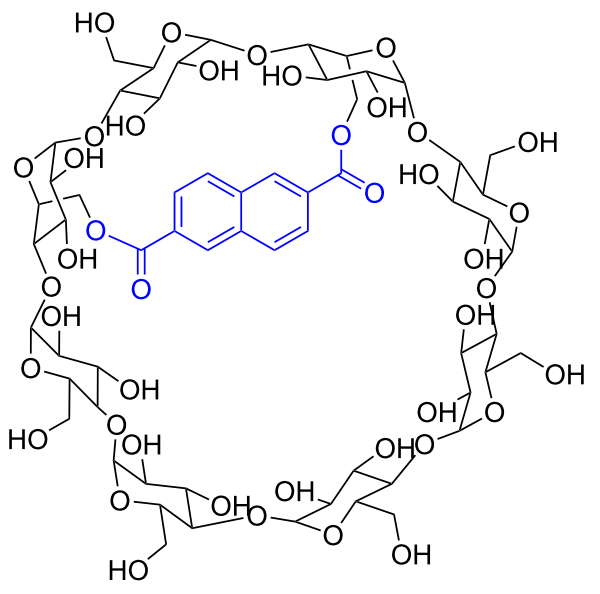

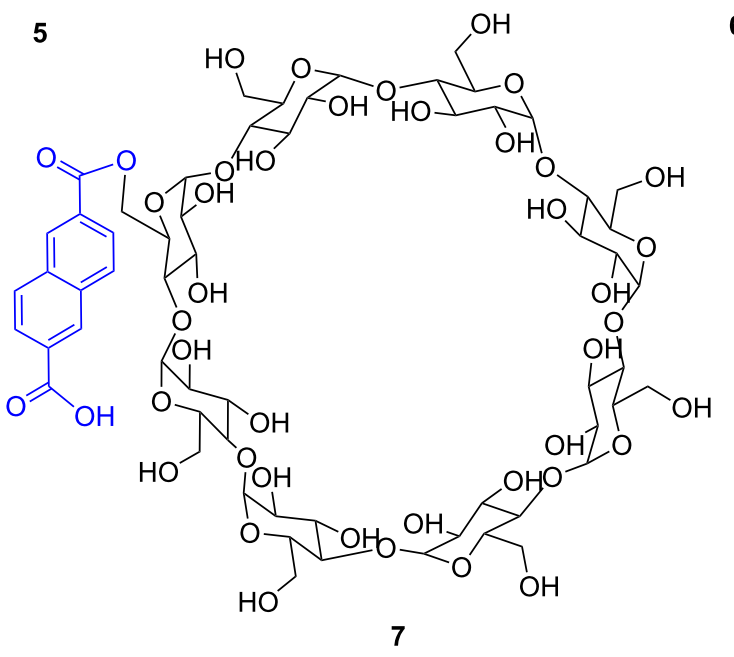

Scheme 1: Biphenyl-capped (5), naphthalene-capped (6), and naphthalene-appended y-cyclodextrin (7). 
exploring and comparing the performance of various chiral hosts, such as cyclodextrins (CDs), proteins and chiral hydrogen-bonding templates. $\gamma$-CD can significantly accelerate the photocyclodimerization of AC by forming a 1:2 host-guest complex with $\mathrm{AC}$ in aqueous solutions [12]. Altering the chiral environment of $\gamma$-CD by rim modification is a convenient, yet effective, tool for manipulating the stereoselectivity of AC photocyclodimerization. In our previous studies, we have shown that a capping modification of $\gamma$-CD causes a dramatic switching of stereoselectivity in AC photodimerization [12,22]. Thus, by using native $\gamma$-CD the chiral cyclodimer 2 is obtained in $41 \%$ enantiomeric excess (ee), whereas biphenyl-capped $\gamma$-CD 5 yields antipodal 2 in $-57 \%$ ee (Scheme 1) [22]: Where the positive/negative sign of ee indicates a higher yield of first/ second eluted enantiomer detected on the chiral HPLC analysis. These observations prompted us to design and synthesize a more rigidly capped $6^{\mathrm{A}}, 6^{\mathrm{C}}-(2,6-$ naphthalenedicarboxyl)- $\gamma-\mathrm{CD}$ 6. This modification further enabled us to trigger the photocyclodimerization via Förster resonance energy transfer (FRET) sensitization.

\section{Results and Discussion}

Naphthalene-capped $\gamma$-CD 6 was synthesized by the reaction of $6^{\mathrm{A}}, 6^{\mathrm{C}}$-ditosyl- $\gamma$-CD [23] with disodium 2,6-naphthalenedicarboxylate in DMSO. An attempt to synthesize the regioisomeric $6^{\mathrm{A}}, 6^{\mathrm{D}}-\left(2,6\right.$-naphthalenedicarboxyl)- $\gamma$-CD by reacting $6^{\mathrm{A}}, 6^{\mathrm{D}}$ ditosyl- $\gamma$-CD with disodium 2,6-naphthalenedicarboxylate was unsuccessful, presumably due to the longer distance between the A and D glucose units to be bridged by the 2,6-naphthalenedicarboxylate unit. For the purposes of comparison, naphthalene-appended $\gamma$-CD 7 was synthesized by reacting $\gamma$-CD with 2,6-naphthalenedicarboxylic acid. Modified $\gamma$-CD 7 was found to be sparingly soluble in water, probably due to the intermolecular aggregation of 7 by successive penetration of the naphthalene moiety into the cavity of another CD. The solubility of 7 was significantly enhanced by adding sodium carbonate. In contrast, capped $\gamma$-CD 6 showed a much higher solubility in water, as the naphthalene cap can hardly interact with another $\mathrm{CD}$.

The complexation behavior of AC with modified $\gamma$-CDs 6 and 7 was investigated by UV-vis, circular dichroism and fluorescence spectral studies. As shown in Figure 1, the addition of 7 to an aqueous solution of $\mathrm{AC}(0.2 \mathrm{mM})$ caused an evident bathochromic shift of the ${ }^{1} L_{\mathrm{a}}$ band of AC, which is probably due to the stacking complexation of two AC molecules in a single $\gamma$-CD cavity.

Modified $\gamma$-CDs 6 and 7 showed moderate circular dichroism signals in the naphthalene-absorbing region. As shown in Figure 2, naphthalene-appended $\gamma$-CD 7 at $0.2 \mathrm{mM}$ concentra-

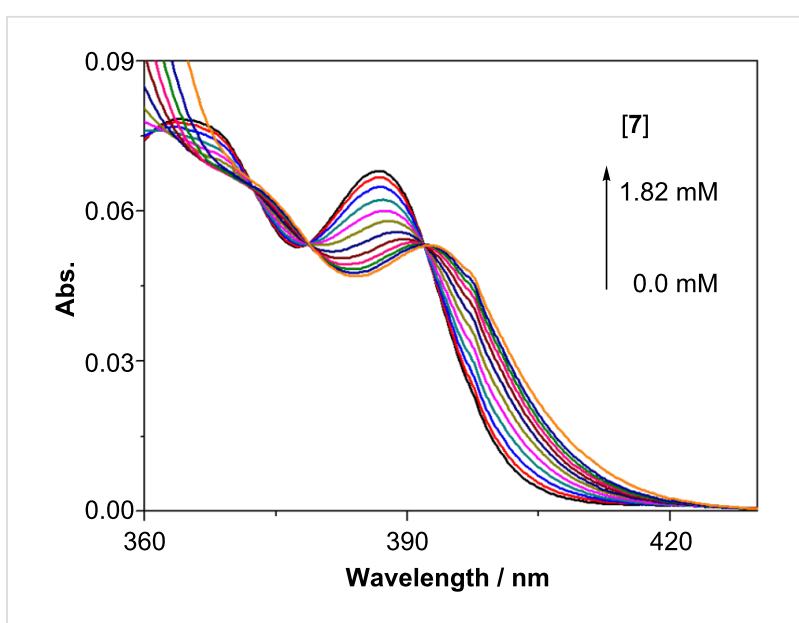

Figure 1: UV-vis spectral changes of $0.2 \mathrm{mM} \mathrm{AC}$ upon increasing the concentration of 7 in $\mathrm{pH} 9$ phosphate buffer at $25^{\circ} \mathrm{C}$.

tion gave a bisignate circular dichroism signal even in the absence of AC. As the intensity $(\Delta \varepsilon)$ decreased at lower concentrations, this bisignate signal is thought to be a real exciton couplet arising from the self-aggregation of 7 , where the included naphthalene chromophores are arranged in a righthanded screw [24]. As can be seen from Figure 3, naphthalenecapped $\gamma$-CD 6 gave only weak induced circular dichroism signals at the ${ }^{1} L_{\mathrm{a}}$ and ${ }^{1} B_{\mathrm{b}}$ bands of the naphthalene chromophore, the intensity of which was not concentration-dependent.

The addition of AC $(0-0.26 \mathrm{mM})$ to the above solutions of 7 or $6(0.2 \mathrm{mM})$ produced a strong positive exciton couplet at the ${ }^{1} B_{\mathrm{b}}$ transition of AC (Figure 2 and Figure 3 ) which overwhelmed the inherent signals. The positive couplet observed indicates the right-handed helical conformation of the two AC molecules in the $\gamma$-CD cavity [24].

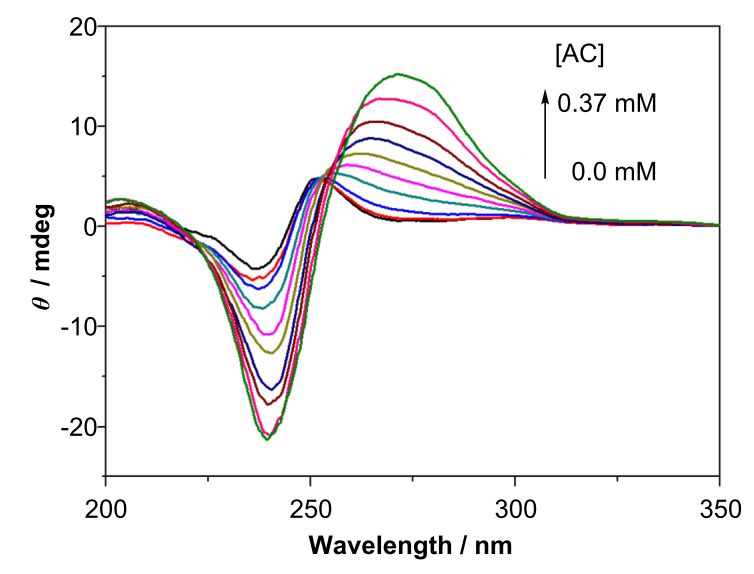

Figure 2: Circular dichroism spectra of $7(0.2 \mathrm{mM})$ in the presence of $0,0.0083,0.025,0.048,0.071,0.093,0.13,0.16,0.22,0.27$ and 0.37 $\mathrm{mM} \mathrm{AC}$ in $\mathrm{pH} 9$ phosphate buffer at $20^{\circ} \mathrm{C}$. 


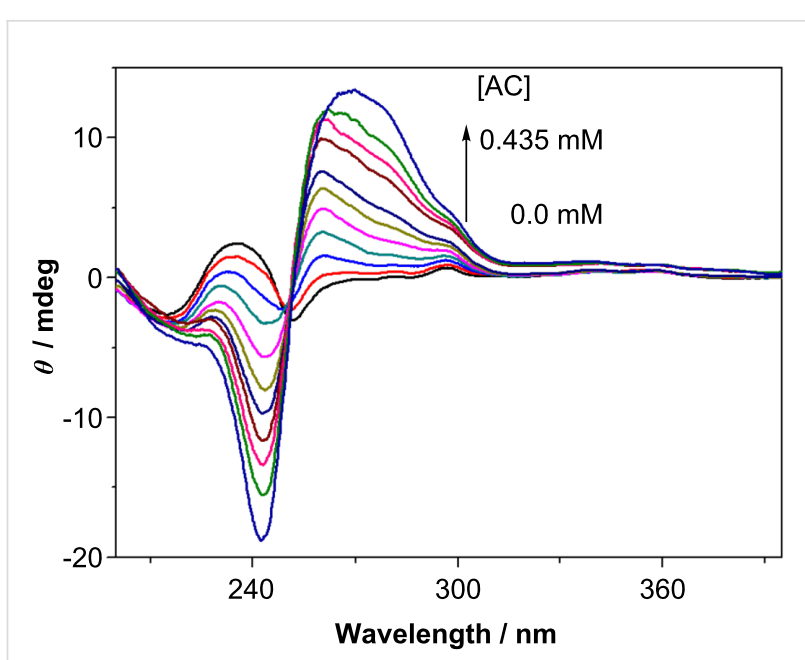

Figure 3: Circular dichroism spectra of $6(0.2 \mathrm{mM})$ in the presence of $0,0.0083,0.025,0.048,0.071,0.093,0.11,0.15,0.18,0.21$ and 0.26 $\mathrm{mM} \mathrm{AC}$ in $\mathrm{pH} 9$ phosphate buffer at $20^{\circ} \mathrm{C}$.

Fluorescence spectral behavior was examined at a lower host concentration in order to observe the fluorescence from both the $1: 1$ and 1:2 complexes with AC. Upon the addition of AC $(0-0.05 \mathrm{mM})$ to a solution of $7(0.02 \mathrm{mM})$, the naphthalene fluorescence at $373 \mathrm{~nm}$ was gradually reduced in intensity with an accompanying increase of AC fluorescence at $426 \mathrm{~nm}$ (Figure 4). The reduction of fluorescence intensity amounted to $27 \%$ at an $\mathrm{AC}$ concentration of $0.0375 \mathrm{mM}$, even although the absorbance of $0.0375 \mathrm{mM} \mathrm{AC}$ is only $11 \%$ of $0.02 \mathrm{mM}$ naphthalene at the excitation wavelength $(296 \mathrm{~nm})$ and the internal filter effect of AC at $350-400 \mathrm{~nm}$ is negligible (absorbance $<0.1$ ). Considering the nice spectral overlap of the naphthalene fluorescence with the AC absorption (Figure 4), we conclude that Förster resonance energy transfer (FRET) is operating from naphthalene-appended 7 to AC residing in the cavity. Further addition of AC up to $0.05 \mathrm{mM}$ caused a global decrease of the fluorescence of both 7 and $\mathrm{AC}$, which can be rationalized by the increased formation of a 1:2 complex at the higher AC concentration, leading to efficient FRET and photocyclodimerization in the cavity.

Nonlinear least-squares fits of the UV-vis spectral titration data to the stepwise 1:2 complexation model gave binding constants for each step: $K_{1}=1050 \mathrm{M}^{-1}$ and $K_{2}=18600 \mathrm{M}^{-1}$ for 6 and $K_{1}=620 \mathrm{M}^{-1}$ and $K_{2}=22300 \mathrm{M}^{-1}$ for 7 at $25{ }^{\circ} \mathrm{C}$. When compared to the corresponding values reported for native $\gamma-\mathrm{CD}$ $\left(K_{1}=182 \mathrm{M}^{-1}\right.$ and $\left.K_{2}=56700 \mathrm{M}^{-1}\right)$ [12], the first binding constant was enhanced by a factor of $3.5-5.8$ by introducing the naphthalene moiety, whilst the second binding constant was reduced by a factor of 2.5-3.0, thus making the overall binding constant $\left(K_{1} K_{2}\right)$ approximately twice as high. It is known that the small $K_{1}$ for native $\gamma$-CD is due to the oversized cavity

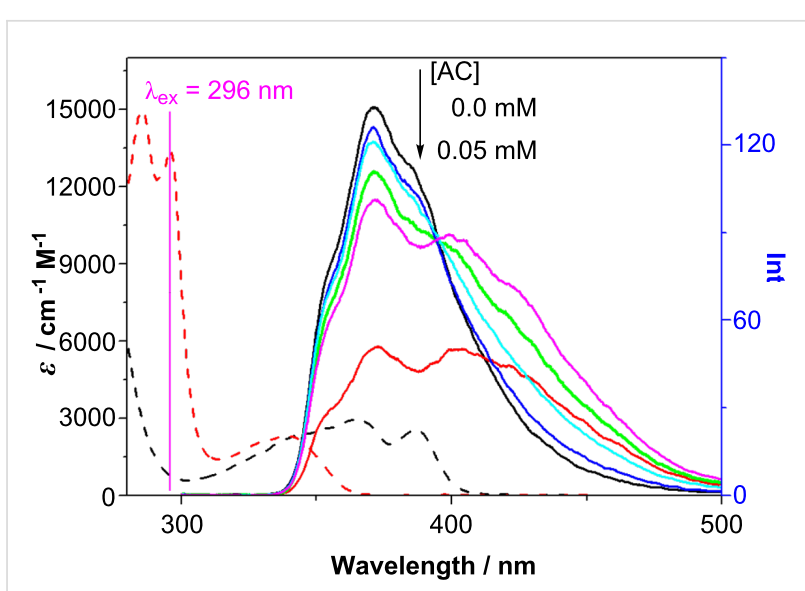

Figure 4: UV-vis spectra of AC (black dashed line) and 7 (red dashed line) and fluorescence spectra of $7(0.02 \mathrm{mM})$ in the presence of 0.0 , $0.0041,0.0125,0.025,0.0375$ and $0.05 \mathrm{mM} \mathrm{AC}$ in $\mathrm{pH} 9$ phosphate buffer at $20^{\circ} \mathrm{C}$. $\lambda_{\mathrm{ex}}=296 \mathrm{~nm}$.

which cannot provide tight contacts for a single AC molecule. Only when a second AC is introduced into the same cavity, are close contacts possible for two AC molecules with $\gamma$-CD walls thus leading to a much larger $K_{2}$. We attribute the enhanced $K_{1}$ values for $\mathbf{6}$ and 7 to the increased hydrophobicity of the naphthalene-modified $\gamma$-CD cavity. On the contrary, the naphthalene moieties reduce the $K_{2}$ values, probably due to steric hindrance and the restricted conformation and orientation available for ACs in the cavity. The higher overall affinities $\left(K_{1} K_{2}\right)$ for $\mathbf{6}$ and 7 than for native $\gamma$-CD indicate the positive effect of aromatic modification on AC complexation.

An aqueous buffer solution ( $\mathrm{pH} 9)$ of $\mathrm{AC}(0.4 \mathrm{mM})$ and modified $\gamma$-CD $(2 \mathrm{mM})$ was photoirradiated at $360 \mathrm{~nm}$ with a Xenon lamp fitted with a band-pass filter. The product distribution and the ee of chiral photodimers, both determined by chiral HPLC, are shown in Table 1. As a general tendency, the HH dimers were preferred by introducing the aromatic substituents. Thus, the $\mathrm{HH} / \mathrm{HT}$ ratio was dramatically enhanced from 0.12 for native $\gamma$-CD to $0.4-1.0$ for biphenyl- or naphthalene-modified $\gamma$-CDs 5-7. In particular, the use of the capped $\gamma$-CD 6 led to the preferential formation of chiral 3 in $34 \%$ yield at $0{ }^{\circ} \mathrm{C}$. The increased hydrophobicity around the primary rim of these modified $\gamma$-CDs favors inclusion of the non-polar aromatic part of $\mathrm{AC}$ near the primary portal and the polar carboxylate part near the secondary portal to give the HH-oriented precursor complex. In contrast, the HT-oriented precursor complex, in which one of AC's carboxylate is positioned at the primary rim, should be less stable due to increased hydrophobicity, leading to the switching of product population to HH dimers.

Closer examination of the product distributions revealed the contrasting behavior of the anti/syn ratio in HT versus HH 
Table 1: Photocyclodimerization of 2-anthracenecarboxylate $(A C)$ in the presence of native and modified $\mathrm{y}$-cyclodextrins (CDs) ${ }^{\mathrm{a}}$

\begin{tabular}{|c|c|c|c|c|c|c|c|c|c|c|c|c|}
\hline \multirow{2}{*}{ host } & \multirow{2}{*}{$\lambda / \mathrm{nm}^{\mathrm{b}}$} & \multirow{2}{*}{$\mathrm{CD} / \mathrm{AC}^{\mathrm{C}}$} & \multirow{2}{*}{$T /{ }^{\circ} \mathrm{C}$} & \multicolumn{4}{|c|}{ relative yield $/ \% \mathrm{~d}$} & \multirow{2}{*}{$\mathrm{HH} / \mathrm{HT}^{\mathrm{e}}$} & \multicolumn{2}{|c|}{ anti/syn } & \multicolumn{2}{|c|}{$\mathrm{ee} / \% \mathrm{~d}, \mathrm{f}$} \\
\hline & & & & 1 & 2 & 3 & 4 & & $1 / 2$ & $3 / 4$ & 2 & 3 \\
\hline$\gamma-C D^{g}$ & 365 & 5 & 0 & 43 & 46 & 6 & 5 & 0.12 & 0.9 & 1.2 & 41 & -1 \\
\hline $5^{h}$ & 365 & 5 & 0 & 39 & 28 & 20 & 13 & 0.49 & 1.4 & 1.5 & -58 & -14 \\
\hline \multirow[t]{7}{*}{6} & 360 & 5 & 35 & 40 & 30 & 23 & 7 & 0.43 & 1.3 & 3.3 & 16 & 18 \\
\hline & & 5 & 20 & 38 & 29 & 25 & 9 & 0.51 & 1.3 & 2.8 & 20 & 21 \\
\hline & & 5 & 10 & 34 & 25 & 30 & 11 & 0.69 & 1.4 & 2.7 & 23 & 25 \\
\hline & & 5 & 0 & 29 & 23 & 34 & 13 & 0.90 & 1.3 & 2.6 & 29 & 30 \\
\hline & & 0.3 & 0 & 36 & 33 & 22 & 9 & 0.45 & 1.1 & 2.4 & 15 & 18 \\
\hline & 300 & 5 & 0 & 27 & 22 & 36 & 15 & 1.04 & 1.2 & 2.4 & 28 & 35 \\
\hline & & 0.3 & 0 & 28 & 26 & 32 & 14 & 0.85 & 1.1 & 2.3 & 24 & 30 \\
\hline \multirow[t]{5}{*}{7} & 360 & 5 & 35 & 39 & 33 & 15 & 13 & 0.39 & 1.2 & 1.2 & 26 & -1 \\
\hline & & 5 & 25 & 39 & 33 & 15 & 14 & 0.40 & 1.2 & 1.1 & 33 & 4 \\
\hline & & 5 & 15 & 37 & 35 & 15 & 13 & 0.39 & 1.1 & 1.2 & 28 & -5 \\
\hline & & 5 & 0 & 37 & 34 & 14 & 14 & 0.39 & 1.1 & 1.0 & 37 & -4 \\
\hline & 300 & 5 & 0 & 39 & 30 & 14 & 17 & 0.45 & 1.3 & 0.8 & 32 & -5 \\
\hline
\end{tabular}

alradiated in $\mathrm{pH} 9$ aqueous buffer at $0-35^{\circ} \mathrm{C}$ with a Xenon lamp fitted with a band-pass filter; $[\mathrm{AC}]=0.4 \mathrm{mM}$ (fixed); [CD] = 0.12 or $2 \mathrm{mM}$. bIrradiation wavelength. CHost-guest ratio. dRelative yield and ee determined by chiral HPLC on a tandem column of Intersil ODS-2 (GL Science) and Chiralcel OJ-R (Daicel); error in ee: $\pm 0.7 \% .^{e}(3+4) /(1+2) .{ }^{f}$ Positive/negative ee sign corresponds to the excess of the first/second-eluted enantiomer, respectively. ${ }^{g}$ Ref [12]. ${ }^{\text {h }}$ ef [20].

dimers. As can be seen from the anti/syn ratios for the HT and HH dimers shown in Table 1, the modifications of $\gamma$-CD only slightly alter the $\mathbf{1} / \mathbf{2}$ ratio from 0.9 for native $\gamma$-CD to $1.1-1.4$ for 5-7. In sharp contrast, the 3/4 ratio was more susceptible to rim modification, in particular rigid capping was enhanced from 1.2 for native $\gamma$-CD to 1.5 for biphenyl-capped 5 and even to 2.3-3.3 for naphthalene-capped $\mathbf{6}$, but was practically unaffected at 1.0-1.2 for naphthalene-appended 7. These results are quite reasonable, as the electrostatic repulsion of the carboxylate anions of two ACs in the CD cavity should be stronger in an HH-oriented complex than in an HT-oriented one due to the shorter inter-anion distance in the former. In summary, naphthalene-capping greatly enhances the formation of $\mathrm{HH}$, in particular anti-HH, dimers as a combined effect of increased hydrophobicity and electrostatic repulsion.

The hydrophobic modifications at the primary rim reduced the ee of chiral HT dimer 2, suggesting that the achiral substituent introduced altered the chiral environment of $\gamma$-CD cavity. In this context, it is interesting to note that naphthalene-capped $\mathbf{6}$ and naphthalene-appended 7 give $\mathbf{2}$ in $29 \%$ and $37 \%$ ee, respectively, which are only slightly smaller than that obtained with native $\gamma$-CD $(41 \%$ ee), whereas biphenyl-capped 5 gave antipodal 2 in $-58 \%$ ee under comparable conditions (Table 1). Molecular model examinations indicated that the biphenyl group, attached to the A and D glucose units of $\gamma$-CD $\mathbf{5}$, covers half of the primary rim. In the HT-oriented precursor complex of $\mathrm{AC}$ with $\mathbf{5}$, one of the carboxylate groups is inevitably exposed to the bulk water through the narrowed primary rim, leading to a highly restricted conformation, which significantly differs from the original one achieved in the native $\gamma$-CD cavity. In contrast, the naphthalene moiety is anchored to only one glucose unit in 7 or to the $\mathrm{A}$ and $\mathrm{C}$ glucose units in $\mathbf{6}$, leaving a larger opening for the carboxylate tail of the $\mathrm{AC}$ and more freedom for the HT-oriented AC pair in the cavity, a situation similar to native $\gamma$-CD. Based on these considerations, we may conclude that the steric restriction caused by the capping group, rather than its rigidity, is the real cause of the chirality switching observed for $\mathbf{5}$.

Interestingly, the use of naphthalene-capped 6 greatly improved the chemical and optical yields of 3 , while native $\gamma-C D$, biphenyl-capped 5, and naphthalene-appended 7 afforded almost racemic or antipodal $\mathbf{3}$ in much smaller chemical and optical yields. The HH-oriented AC pair in a complex precursor to $\mathbf{3}$ is likely to conceal the hydrophobic anthracene moiety inside the cavity with the carboxylate groups being exposed to the bulk water near the secondary rim of $\gamma-\mathrm{CD}$. The enhanced chemical and optical yields observed for 3 should reflect the totally altered chiral environment, which favors the formation of one of the diastereomeric $\mathrm{HH}$-oriented precursor complexes in the modified CD cavity of $\mathbf{6}$. By lowering the temperature to $0{ }^{\circ} \mathrm{C}$, the system was optimized to give anti-HH 3 in $34 \%$ yield with an ee of $30 \%$, which is much higher than the corresponding values obtained with native or any other capped $\gamma$-CDs so far examined in aqueous solutions [20,22]. 
We further examined indirect FRET excitation (intramolecular photosensitization) of AC included in host 6. Mechanistically, FRET excitation of AC is highly advantageous from the photochirogenic point of view, since the static energy transfer to an $\mathrm{AC}$ molecule accommodated in the $\mathrm{CD}$ cavity is much faster and more efficient than the dynamic energy transfer to an AC in bulk solution (even if it exists), thus minimizing the unfavorable achiral "outside" photoreaction. Irradiation of an aqueous solution containing $0.4 \mathrm{mM} \mathrm{AC}$ and $2 \mathrm{mM} 6$ was performed at $300 \mathrm{~nm}$, where $98.5 \%$ of the incident light was absorbed by the naphthalene moiety of $\mathbf{6}$ and therefore it is possible to examine the effects of FRET excitation on the distribution and ee of cyclodimers. As can be seen from Table 1, FRET excitation at $300 \mathrm{~nm}$ gave 3 in $36 \%$ yield and $35 \%$ ee, both of which are appreciably higher than the corresponding values obtained upon direct $\mathrm{AC}$ excitation at $360 \mathrm{~nm}$. The enhanced stereoselectivity is attributed to the smaller contribution of the photoreaction outside the CD cavity, where the HT dimers are favored and chiral 2 and 3 produced should be racemic. To the best of our knowledge, this is the first example of FRET sensitization applied to photochirogenesis.

In supramolecular photochirogenesis, an excess amount of the chiral host is often the prerequisite for minimizing contamination from undesirable racemic photoreactions occurring outside chiral host. In the present system, it is likely that only AC that is included in the CD cavity can be FRET-sensitized by naphthalene, since the FRET efficiency is inversely proportional to the sixth power of donor-acceptor distance. We expected therefore that the AC photocyclodimerization could be catalyzed even with a sub-equivalent amount of the chiral FRET host. Indeed, the FRET-sensitized photocyclodimerization of AC with 0.3 equiv of $\mathbf{6}$ gave dimer 3 in 32\% yield and 30\% ee, which are only slightly decreased from the original $36 \%$ yield and $35 \%$ ee obtained with 5 equiv of $\mathbf{6}$ (Table 1). In contrast, the chemical yield of 3 was reduced from $34 \%$ to $22 \%$ and the ee from $30 \%$ to $18 \%$ upon direct $\mathrm{AC}$ excitation at $360 \mathrm{~nm}$.

\section{Conclusion}

In the present work, naphthalene-appended and -capped $\gamma$-CDs were synthesized to investigate the effects of naphthalene capping and of FRET excitation on the complexation and supramolecular photochirogenic behavior of AC. Compared to native $\gamma-\mathrm{CD}$, the naphthalene-modified $\gamma$-CDs showed 3.5-5.8 fold larger first binding constants and 2.5-3.0 fold smaller second binding constants, which resulted in roughly two-fold larger overall affinities, due to increased cavity hydrophobicity. Fluorescence spectral examination revealed that the FRET from the excited naphthalene on $\mathrm{CD}$ rim to $\mathrm{AC}$ included in the $\mathrm{CD}$ cavity is operative upon excitation of the naphthalene chromophore at $296 \mathrm{~nm}$. Circular dichroism spectral studies revealed that the two AC molecules are arranged in a right-handed screw sense in the CD cavity. Direct excitation at $360 \mathrm{~nm}$ of AC accommodated in the cavity of modified $\gamma-\mathrm{CD}$ afforded $\mathrm{HH}$ cyclodimers (despite electrostatic repulsion between the $\mathrm{HH}$-oriented carboxylate anions of the AC) in combined yields of up to $51 \%$, which is much higher than that $(11 \%)$ obtained with native $\gamma$-CD. In particular, both the chemical and optical yields of $\mathrm{HH}$ dimer 3 were significantly enhanced from $6 \%$ to $34 \%$ and from $-1 \%$ ee to $30 \%$ ee by introducing a naphthalene-cap to $\gamma$-CD. More interestingly, FRET sensitization by exciting the naphthalene-cap of 6 at $300 \mathrm{~nm}$ afforded $\mathrm{HH}$ dimer 3 in a further enhanced yield of $36 \%$ with an ee of $35 \%$. In the FRET sensitization, the high stereoselectivity was maintained even when the host/guest ratio was reduced to 0.3 , thus achieving catalytic supramolecular photochirogenesis.

\section{Experimental}

General. FAB mass spectra were measured on a JEOL JMSDX303 mass spectrometer. NMR spectra were recorded on a Bruker DRX-600 or a JEOL JNM-EX 400 spectrometer. UV-vis, fluorescence, and circular dichroism spectra were recorded in a UNISOKU USP-203CD cryostat with a JASCO V-560 spectrophotometer, JASCO FP-6500 luminescence spectrometer, and JASCO J-810 spectropolarimeter, respectively. Photoirradiation was performed in a UNISOKU USP-203 cryostat with an appropriate interference filter for $300 \mathrm{~nm}$ or $360 \mathrm{~nm}$. Irradiated samples were subjected to chiral HPLC analysis on a tandem column of Intersil ODS-2(GL Science) and Chiralcel OJ-R (Daicel) with a 36:64 mixture of acetonitrile and water as eluent [12].

Syntheses of modified $\boldsymbol{\gamma}$-CDs 6 and 7. For $6: 6^{\mathrm{A}}, 6^{\mathrm{C}}$-ditosyl- $\gamma$ $\mathrm{CD}(321 \mathrm{mg}, 0.2 \mathrm{mmol}$ ) and disodium 2,6-naphthalenedicarboxylate (52 mg, $0.2 \mathrm{mmol}$ ) were dissolved in $10 \mathrm{~mL}$ DMSO, and the mixture heated at $90{ }^{\circ} \mathrm{C}$ for $3 \mathrm{~d}$. After cooling, the solution was concentrated to $0.5 \mathrm{~mL}$ under vacuum, trifluoroacetic acid added and the solution added dropwise to $30 \mathrm{~mL}$ acetone to give a precipitate. The precipitate was collected by filtration and purified by reverse-phase chromatography to give pure 6 (15.3 $\mathrm{mg}, 5.2 \%$ yield). ${ }^{1} \mathrm{H}$ NMR (400 MHz, $\left.\mathrm{D}_{2} \mathrm{O}\right): \delta 8.14(1 \mathrm{H}, \mathrm{s})$, $8.02(1 \mathrm{H}, \mathrm{s}), 7.78(1 \mathrm{H}, \mathrm{d}, J=8.4 \mathrm{~Hz}), 7.69(1 \mathrm{H}, \mathrm{d}, J=8.6 \mathrm{~Hz})$, $7.62(2 \mathrm{H}, \mathrm{d}, J=8.6 \mathrm{~Hz}), 4.97(7 \mathrm{H}, \mathrm{m}), 4.88(2 \mathrm{H}, \mathrm{m}), 4.79(2 \mathrm{H}$, $\mathrm{m}), 4.39(2 \mathrm{H}, \mathrm{m}), 4.31(1 \mathrm{H}, \mathrm{m}),, 4.18(1 \mathrm{H}, \mathrm{m}), 3.99-3.64(13 \mathrm{H}$, $\mathrm{m}), 3.63-3.31(19 \mathrm{H}, \mathrm{m}), 3.13(4 \mathrm{H}, \mathrm{m}), 2.56(1 \mathrm{H}, \mathrm{d}, J=11.0$ $\mathrm{Hz}$ ), 2.39 (1H, d, $J=11.1 \mathrm{~Hz}$ ), $2.27(1 \mathrm{H}, \mathrm{d}, J=11.2 \mathrm{~Hz}$ ), 2.21 $(1 \mathrm{H}, \mathrm{m}), 1.60(1 \mathrm{H}, \mathrm{br}) .{ }^{13} \mathrm{C} \mathrm{NMR}\left(150 \mathrm{MHz}, \mathrm{D}_{2} \mathrm{O}\right): \delta 167.85$, 166.52, 133.85, 133.41, 132.71, 132.25, 131.98, 129.86, 129.50, 128.72, 125.94, 125.38, 102.36, 102.01, 101.84, 101.75, 101.67, $101.53,81.21,80.70,80.07,79.74,74.86,73.57,73.26,72.99$, $72.81,72.69,72.61,72.49,72.31,72.06,71.94,71.83,71.68$, $71.53,71.22,70.55,68.13,66.09,60.23,60.04,59.91,59.83$, 
58.52. HR-FAB-MS: Calc. for $[6+N a]^{+}, \mathrm{C}_{60} \mathrm{H}_{86} \mathrm{NaO}_{42}$ 1499.43, found: 1499.43 .

For 7: 2,6-naphthalenedicarboxylic acid (216 mg, $1 \mathrm{mmol})$ and $\gamma$-CD (1296 mg, $1 \mathrm{mmol}$ ) were dissolved in $10 \mathrm{~mL} \mathrm{DMF}$, to which DCC (310 mg, $1.5 \mathrm{mmol}$ ) and HOBT (54 mg, $0.4 \mathrm{mmol}$ ) were added and the solution stirred at room temperature for $2 \mathrm{~d}$. The reaction mixture was poured into $150 \mathrm{~mL}$ dry acetone to give a white precipitate. The precipitate was collected by filtration, dissolved in $10 \%$ aqueous methanol and then subjected to reverse-phase HPLC separation to give 7 (194 mg, 13\% yield). ${ }^{1} \mathrm{H}$ NMR $\left(600 \mathrm{MHz}, 4: 1\right.$ DMSO- $\left.d_{6}-\mathrm{D}_{2} \mathrm{O}\right): \delta 8.58(1 \mathrm{H}, \mathrm{d}, J=$ $12.4 \mathrm{~Hz},), 8.54(1 \mathrm{H}, \mathrm{s}), 8.13(1 \mathrm{H}, \mathrm{dd}, J=8.5,2.6 \mathrm{~Hz}),$, $(1 \mathrm{H}, \mathrm{d}, J=8.5 \mathrm{~Hz}),, 7.99(1 \mathrm{H}, \mathrm{d}, J=8.8 \mathrm{~Hz}), 7.96(1 \mathrm{H}, \mathrm{d}, J=$ $8.6 \mathrm{~Hz},), 4.93(1 \mathrm{H}, \mathrm{d}, J=3.3 \mathrm{~Hz}), 4.89(1 \mathrm{H}, \mathrm{d}, J=3.3 \mathrm{~Hz}), 4.83$ $(6 \mathrm{H}, \mathrm{m}), 4.64(1 \mathrm{H}, \mathrm{m}), 4.36(1 \mathrm{H}, \mathrm{m}), 3.66-3.52(24 \mathrm{H}, \mathrm{m})$, $3.52-3.39$ (14H, m), 3.38-3.26 (18H, m). ${ }^{13} \mathrm{C} \mathrm{NMR} \mathrm{(150} \mathrm{MHz,}$ $\left.4: 1 \mathrm{DMSO}-d_{6}-\mathrm{D}_{2} \mathrm{O}\right) \delta 167.71,166.09,149.51,137.12,134.64$, $130.64,130.49,129.11,126.42,126.01,124.42,102.84,102.01$, $101.81,82.30,81.25,81.17,81.12,81.04,80.73,73.30,73.07$, 72.97, 72.70, 72.47, 72.39, 69.46, 64.89, 60.22, 60.08, 59.89. HR-FAB-MS: Calc. for $[7+\mathrm{Na}]^{+}, \mathrm{C}_{60} \mathrm{H}_{86} \mathrm{NaO}_{43}$ 1517.44, found: 1517.45 .

\section{Supporting Information}

\section{Supporting Information File 1}

NMR and HR-MS data of compounds 6 and 7.

[http://www.beilstein-journals.org/bjoc/content/ supplementary/1860-5397-7-38-S1.pdf]

\section{Acknowledgements}

This work was supported by JST (CY and YI), JSPS (YI). QW thanks the Student Exchange Support Program of JASSO for financial support for her stay in Japan.

\section{References}

1. Inoue, Y. Chem. Rev. 1992, 92, 741-770. doi:10.1021/cr00013a001

2. Inoue, Y.; Ramamurthy, Y., Eds. Chiral Photochemistry; Molecular and Supramolecular Photochemistry; Marcel Dekker: New York, 2004; Vol. 11. doi:10.1201/9780203026342

3. Griesbeck, A. G.; Meierhenrich, U. J. Angew. Chem., Int. Ed. 2002, 41, 3147-3154.

doi:10.1002/1521-3773(20020902)41:17<3147::AID-ANIE3147>3.0.CO ;2-V

4. Yang, C.; Inoue, Y. Supramolecular Photochirogenesis with Cyclodextrin. In Cyclodextrin Materials Photochemistry, Photophysics and Photobiology; Douhal, A., Ed.; Elsevier: Amsterdam, 2006; pp 241-265. doi:10.1016/B978-044452780-6/50012-7

5. Inoue, Y. Nature 2005, 436, 1099-1100. doi:10.1038/4361099a

6. Bauer, A.; Westkämper, F.; Grimme, S.; Bach, T. Nature 2005, 1139-1140. doi:10.1038/nature03955
7. Inoue, Y.; Dong, F.; Yamamoto, K.; Tong, L.-H.; Tsuneishi, H.; Hakushi, T.; Tai, A. J. Am. Chem. Soc. 1995, 117, 11033-11034. doi:10.1021/ja00149a037

8. Lu, R.; Yang, C.; Cao, Y.; Wang, Z.; Wada, T.; Jiao, W.; Mori, T.; Inoue, Y. Chem. Commun. 2008, 374-376. doi:10.1039/b714300a

9. Sivaguru, J.; Natarajan, A.; Kaanumalle, L. S.; Shailaja, J.; Uppili, S.; Joy, A.; Ramamurthy, V. Acc. Chem. Res. 2003, 36, 509-521. doi:10.1021/ar020269i

10. Aechtner, T.; Dressel, M.; Bach, T. Angew. Chem., Int. Ed. 2004, 43, 5849-5851. doi:10.1002/anie.200461222

11. Nishioka, Y.; Yamaguchi, T.; Kawano, M.; Fujita, M. J. Am. Chem. Soc. 2008, 130, 8160-8161. doi:10.1021/ja802818t

12. Nakamura, A.; Inoue, Y. J. Am. Chem. Soc. 2003, 125, 966-972. doi:10.1021/ja016238k

13. Wada, T.; Nishijima, M.; Fujisawa, T.; Sugahara, N.; Mori, T.; Nakamura, A.; Inoue, Y. J. Am. Chem. Soc. 2003, 125, 7492-7493. doi:10.1021/ja034641g

14. Nakamura, A.; Inoue, Y. J. Am. Chem. Soc. 2005, 127, 5338-5339. doi:10.1021/ja050704e

15. Nishijima, M.; Wada, T.; Mori, T.; Pace, T. C. S.; Bohne, C.; Inoue, Y. J. Am. Chem. Soc. 2007, 129, 3478-3479. doi:10.1021/ja068475z

16. Yang, C.; Mori, T.; Origane, Y.; Ko, Y. H.; Selvapalam, N.; Kim, K.; Inoue, Y. J. Am. Chem. Soc. 2008, 130, 8574-8575. doi:10.1021/ja8032923

17. Ke, C.; Yang, C.; Mori, T.; Wada, T.; Liu, Y.; Inoue, Y. Angew. Chem., Int. Ed. 2009, 48, 6675-6677. doi:10.1002/anie.200902911

18. Yang, C.; Fukuhara, G.; Nakamura, A.; Origane, Y.; Fujita, K.; Yuan, D.-Q.; Mori, T.; Wada, T.; Inoue, Y. J. Photochem. Photobiol., A: Chem. 2005, 173, 375-383. doi:10.1016/j.jphotochem.2005.04.017

19. Yang, C.; Nakamura, A.; Fukuhara, G.; Origane, Y.; Mori, T.; Wada, T.; Inoue, Y. J. Org. Chem. 2006, 71, 3126-3136. doi:10.1021/jo0601718

20. Yang, C.; Nakamura, A.; Wada, T.; Inoue, Y. Org. Lett. 2006, 8, 3005-3008. doi:10.1021/ol061004x

21. Yang, C.; Nishijima, M.; Nakamura, A.; Mori, T.; Wada, T.; Inoue, Y. Tetrahedron Lett. 2007, 48, 4357-4360. doi:10.1016/j.tetlet.2007.04.104

22. Yang, C.; Mori, T.; Inoue, Y. J. Org. Chem. 2008, 73, 5786-5794. doi:10.1021/jo800533y

23. Fujita, K.; Yamamura, H.; Imoto, T.; Fujioka, T.; Mihashi, K. J. Org. Chem. 1988, 53, 1943-1947. doi:10.1021/jo00244a018

24. Nakanishi, K.; Berova, N. Circular dichroism-principles and applications; Wiley-VCH: New York, 2000. 


\section{License and Terms}

This is an Open Access article under the terms of the Creative Commons Attribution License

(http://creativecommons.org/licenses/by/2.0), which permits unrestricted use, distribution, and reproduction in any medium, provided the original work is properly cited.

The license is subject to the Beilstein Journal of Organic Chemistry terms and conditions:

(http://www.beilstein-journals.org/bjoc)

The definitive version of this article is the electronic one which can be found at:

doi:10.3762/bjoc.7.38 